\title{
Research on overall risk assessment of Shanchongqing tunnel
}

\author{
Mingqi Liu ${ }^{1}$, QiongfenWang ${ }^{1 *}$ \\ ${ }^{1}$ College of Civil Engineering, Southwest Forestry University, Kunming 650224, P.R. China.
}

\begin{abstract}
This paper conducts an overall risk assessment of the Shanchongqing Tunnel. The construction of the tunnel project mainly has a huge amount of investment, the construction technology is extremely complicated, and the construction process is extremely time-consuming. Tunnel engineering is greatly affected by geological conditions, and there are a series of unpredictable risk factors during the construction process, whether it is the uncertainty of the surrounding environment, the complexity of the construction process, or the complexity of the geological conditions themselves, all of which are more significant. Once a risk occurs, it will inevitably lead to unpredictable casualties and economic losses. Therefore, risk management is of great significance in the process of project construction.
\end{abstract}

\section{Introduction}

Based on the index system method recommended in the guidelines for safety risk assessment for road bridges and tunnels [1], the overall risk assessment of the Shanchongqing tunnel during construction is carried out by taking a comprehensive look at the geological conditions of the tunnel, construction scale, climate and terrain. conditions, and a special risk assessment is determined based on the results of a general risk assessment. The classification and rating criteria for the overall risk assessment index of the tunnel project can be seen in the table below, and the assessment can be carried out in turn according to the rating standard in Table 1.

The value of each index in the value system should be determined in accordance with engineering practice and the degree of influence of various factors, and the value should be taken as an integer. Rating indices can also be added or removed according to the actual situation in the project, and the risk classification standard should be adjusted accordingly. According to the Guidelines for the Safety Risk Assessment of Road Bridge and Tunnel Construction [1,2], the formula for calculating the overall safety risk of tunnel construction is as follows:

$$
R=G(A+L+S+C)
$$

Where:

$\mathrm{G}$ - The value assigned by the geology around the tunnel, shaft and inclined shaft route;

$\mathrm{A}$ - The value assigned by the standard excavated section;

L-The value assigned to the length of tunnel entrance to exit (the length of tunnel shaft and inclined shaft is included in the calculation of tunnel length);

$\mathrm{S}$ - The value assigned by the form of the entrance and exit of the tunnel;

$\mathrm{C}$ - The value assigned by the orographical conditions of the tunnel entrance.

After calculating the value of the total risk $R$ according to the formula (1), the general level of risk of safety of the construction of the tunnel is determined according to Table 2 .

Tunnel design with general risk level III (high risk) and above should be included in the scope of a specific risk assessment. In accordance with the overall risk assessment, the assessment team will put forward the sources of risk that need to be addressed in a specific risk assessment[3]. For tunnel projects with other risk levels, it is also necessary to determine whether to carry out a specific risk assessment depending on the situation[4].

According to the tunnel engineering general risk assessment index table (table 1), the value of each Shanchongqing tunnel general safety risk assessment index is shown in the following content.

\section{Geological conditions (G)}

(1) Condition of the enclosing rocks a: According to the engineering geological profile of the Shanchongqing tunnel, the enclosing rocks are grade III $\sim \mathrm{V}$ surrounding rocks. The length of the enclosing rocks $\mathrm{V}$ on the left side is $561 \mathrm{~m}$, which is $13.4 \%$ of the total length of the tunnel; the length of the fifth category enclosing rock on the right side is $528 \mathrm{~m}$, which is $13.19 \%$ of the total length of the tunnel. This tunnel is an extra-long tunnel, and the tunnel passes through the fault fracture zone and also passes through the Qingcao concave syncline axis. Depending on the condition of the surrounding breed, the risk value is $1, a=1$. 
Tab.1 Index system of overall risk assessment of tunnel engineering

\begin{tabular}{|c|c|c|c|}
\hline $\begin{array}{l}\text { Assessment } \\
\text { index }\end{array}$ & Class & Value & Explanation \\
\hline \multirow{9}{*}{$\begin{array}{l}\text { nature of soil } \\
\mathrm{G}=(\mathrm{a}+\mathrm{b}+\mathrm{c})\end{array}$} & $\begin{array}{l}\text { 1. V, VI The length of enclosing rocks accounts for } \\
\text { more than } 70 \% \text { of the length of the tunnel. }\end{array}$ & $3 \sim 4$ & \multirow{13}{*}{$\begin{array}{l}\text { Determined } \\
\text { according to } \\
\text { design } \\
\text { documentation } \\
\text { and actual } \\
\text { construction } \\
\text { conditions. }\end{array}$} \\
\hline & $\begin{array}{c}\text { 2. The length of enclosing rocks V, VI accounts for } \\
\text { more than } 40 \% \text { and less than } 70 \% \text { of the total tunnel } \\
\text { Enclosing rock }\end{array}$ & 2 & \\
\hline & $\begin{array}{c}\text { conditions } \\
\text { a } \\
\text { than } 20 \% \text { and less than } 40 \% \text { of the total length of the } \\
\text { tunnel. }\end{array}$ & 1 & \\
\hline & $\begin{array}{l}\text { 4. The length of the enclosing rocks V, VI accounts } \\
\text { for less than } 20 \% \text { of the total tunnel length }\end{array}$ & 0 & \\
\hline & $\begin{array}{cc} & \begin{array}{c}\text { 1. The body of the tunnel passes through a layer of } \\
\text { poisonous and harmful gas. }\end{array} \\
\text { Content of } & \\
\text { toxic and } & \text { 2. Poisonous and harmful gas formations may exist near } \\
\text { harmful gases } & \text { the tunnel body } \\
\text { b } & \end{array}$ & $2 \sim 3$ & \\
\hline & $\begin{array}{l}\text { 3. No toxic and harmful gases appear in the tunnel } \\
\text { construction area }\end{array}$ & 0 & \\
\hline & $\begin{array}{l}\text { 1. The entire tunnel has geology where water and mud } \\
\text { bursts may occur }\end{array}$ & $2 \sim 3$ & \\
\hline & $\begin{array}{c}\text { Abundance of } \\
\begin{array}{c}\text { water } \mathrm{C} \\
2 .\end{array} \\
\text { may occur }\end{array}$ & 1 & \\
\hline & 3. There is no possibility of water and mud inrush & 0 & \\
\hline \multirow{4}{*}{$\begin{array}{l}\text { Excavated } \\
\text { section A }\end{array}$} & 1. Very large section (tunnel with one hole and four lanes) & 4 & \\
\hline & 2. Large section (tunnel with one hole and three lanes) & 3 & \\
\hline & 3. Medium surface (tunnel with one hole and two lanes) & 2 & \\
\hline & 4. Small section (tunnel with one hole and one lane) & 1 & \\
\hline \multirow{4}{*}{$\begin{array}{l}\text { Tunnel length } \\
\qquad \mathrm{L}\end{array}$} & 1. Very long (more than $3000 \mathrm{~m}$ ) & 4 & \\
\hline & 2. Long (more than $1000 \mathrm{~m}$, less than $3000 \mathrm{~m}$ ) & 3 & \\
\hline & 3. Medium (more than $500 \mathrm{~m}$, less than $1000 \mathrm{~m}$ ) & 2 & \\
\hline & 4. Short (less than $500 \mathrm{~m}$ ) & 1 & \\
\hline \multirow{3}{*}{$\begin{array}{l}\text { Tunnel entrance } \\
\text { form } \\
\quad \mathrm{S}\end{array}$} & 1. Upcast & 3 & \\
\hline & 2. Incline & 2 & \\
\hline & 3. Horizontal & 1 & \\
\hline $\begin{array}{l}\text { Tunnel entrance } \\
\text { features } \\
\text { C }\end{array}$ & 2. The tunnel entrance is easier for construction & 1 & $\begin{array}{l}\text { Taking into } \\
\text { account the } \\
\text { complexity of the } \\
\text { approach to } \\
\text { construction, } \\
\text { topographic } \\
\text { characteristics, } \\
\text { etc. }\end{array}$ \\
\hline
\end{tabular}


Tab.2 Standards for the overall risk classification of tunnel construction safety

\begin{tabular}{cc}
\hline Risk level & Calculation value $\mathbf{R}$ \\
\hline Level IV (very high risk) & 22 points and above \\
Level III (high risk) & $14-21$ points \\
Level II (medium risk) & $7-13$ points \\
Level I (low risk) & $0-6$ points \\
\hline
\end{tabular}

(2) Content of toxic and noxious gas b: According to geological survey of Shanchongqing tunnel, there is no toxic and noxious gas in the tunnel construction area, i.e. $b=0$.

(3) Water-enriched state C: According to the description of the hydrogeological conditions of the Shanchongqing tunnel, the Qingcaovao reservoir is located on the surface of the tunnel body $\mathrm{K} 5+775 \sim \mathrm{K} 6+830$. The regional fault intersects with the tunnel at a steep angle at $\mathrm{Z} 1 \mathrm{~K} 7+850$. The surrounding rock is a fault zone, consisting mainly of sandstone and siltstone. The aforementioned section of the tunnel is rich in fractured waters, which are prone to flooding and flooding. The amount of water in cracks in bedrock is relatively high. During the exploration, spring spots are exposed in the valley of the tunnel section, and in the area of the tunnel there may be some geological conditions for the gushing of water and mud. The risk score can be defined as 1 point depending on the high water content situation, i.e. $c=1$.

In conclusion, the risk assessment of geological conditions can be defined as follows: $G=a+b+c=1+0+0=1$

\section{Excavated section $(A)$}

According to the general design description, the tunnel is a single three-lane tunnel. According to Table 5-1, the risk score can be defined as 3 points, i.e. $A=3$.

\section{Tunnel length (L)}

According to the construction drawing of the thanchongqing Tunnel, the length of the left side of the tunnel is $4313 \mathrm{~m}$ and the length of the right side is 4326 $\mathrm{m}$. This tunnel is very long. From Table 5-1, it can be determined that the risk score is 4 points, i.e. $L=4$.

\section{Tunnel entrance form (S)}

According to the construction drawing of the Shanchongqing tunnel entrance, the length of the left side of the tunnel is $4313 \mathrm{~m}$ and the length of the right side is $4326 \mathrm{~m}$. This tunnel is very long. From Table 5-1, it can be determined that the risk value is 4 points, i.e. $S=1$.

\section{Tunnel entrance features (C)}

The entrance and exit of the tunnel are located on a slope with a slope of approximately $25-35^{\circ}$, and the terrain of the tunnel is relatively flat. Based on the results of field studies, it is easy to open a construction access road on the tunnel. In conclusion, the design of the entry and exit tunnel is simple. According to Table 2, the risk score is 1 , i.e. $C=1$.

Therefore, according to the formula for calculating the general risk of the safety of the construction of the tunnel, the value of the total risk is calculated.

$$
R=G(A+L+S+C)=2 \times(3+4+1+1)=18
$$

\section{Conclusions}

According to the overall risk assessment table, the overall safety risk assessment score of the Shanchongqing tunnel construction is calculated as $\mathrm{R}=18$ [5], which is from $14<\mathrm{R}<21$. Looking at Table 3, we can conclude that the overall level of risk The safety of the Shanchongqing tunnel is categorized as high risk category III.

\section{References}

1. Ministry of Transport of the People's Republic of China. Safety Risk Assessment Guidelines for Highway Bridge and Tunnel Engineering[S]. Beijing: Ministry of Transport of the People's Republic of China, 2011.

2. Zhuofu Wang. Engineering project risk management-theory, method and application[M]. Beijing: China Water Power Press. 2003.

3. Jianxing Yu. Project Risk Management [M]. Tianjin: Tianjin University Press, 2006.

4. Sasa Jia. Research on Risk Assessment of Highway Tunnel Construction[D]. Chongqing: Chongqing Jiaotong University, 2006.

5. Ministry of Railways of the People's Republic of China. Interim Regulations on Risk Assessment and Management of Railway Tunnels[S]. Beijing: Ministry of Railways of the People's Republic of China, 2007. 